\title{
Desalination/concentration of reverse osmosis and electrodialysis brines with membrane distillation
}

\author{
M.S. Osman ${ }^{\text {a }}$, J.J. Schoeman ${ }^{\mathrm{b} *}$, L.M. Baratta ${ }^{\mathrm{c}}$ \\ ${ }^{a}$ Department of Chemical Engineering, Water Utilisation Division, University of Pretoria, South Africa, Present address: Sasol \\ Technology, Process Design-Utilities, Secunda, 2302 \\ Tel.+27176193669; fax +27115229511; email: muhammad.osman@sasol.com \\ ${ }^{b}$ Department of Chemical Engineering, Water Utilisation Division, University of Pretoria, South Africa \\ Tel.+27124203569; fax +27123625089; email: japie.schoeman@up.ac.za \\ ${ }^{c}$ Sasol Technology, Research and Development, Sasolburg, 1947 \\ Tel. +27169604909; fax: +27162193011; email: lynette.baratta@sasol.com
}

Received 26 November 2009; accepted 3 May 2010

\begin{abstract}
A B S T R A C T
Brines produced by desalination processes such as reverse osmosis (RO), electrodialysis reversal (EDR) and ion-exchange (IX) holds pollution potential for the water environment if not properly handled. These brines contain a high water content (95-98\%) and chemicals that could possibly be recovered for reuse. Therefore, direct contact membrane distillation (DCMD) which has the potential for water and chemical recovery from brines was investigated for water and chemical recovery from RO and EDR brines originating from difficult to treat petrochemical effluents. It was shown that water recoveries of between $70 \%$ and $80 \%$ could be obtained with membrane distillation (MD). Salt rejections of more than $99.5 \%$ were obtained. The quality of the treated brine is suitable for boiler feed make-up. However, fouling of the membranes took place at high water recovery similarly to as in the last modules in $\mathrm{RO}$ as a result of concentration polarisation and cleaning of the membranes with acid and salt/caustic solution almost restored condensate flux.
\end{abstract}

Keywords: Membrane distillation; Concentration/desalination; Petrochemical effluents; RO brine; EDR brine; Fouling/scaling

\section{Introduction}

The petrochemical industry produces large quantities of saline effluents and brines that need to be disposed of safely $[1,2]$. These saline effluents and brines originate from the desalination of water and process effluents with reverse osmosis (RO), electrodialysis reversal (EDR) and ion-exchange (IX) processes. Large quantities of brine are produced in the process and the brines are usually disposed of into evaporation ponds

${ }^{*}$ Corresponding author
[3]. However, this method of brine disposal could lead to surface and ground water pollution if the brines are not handled correctly. The brines are also a potential source of water and chemicals that could possibly be recovered for reuse.

Evaporative technologies are often used to further concentrate/desalinate brines from RO and EDR plants for effluent volume reduction and water recovery for reuse. However, fouling of the heat exchange surfaces of evaporative technologies often limit the usefulness of this process [4]. Evaporative technologies have the perception to be very energy intensive and 
very expensive. However, some of the evaporative technologies like mechanical vapour compression is not very energy intensive. This technology recollects the latent heat of evaporation similar to as in membrane distillation (MD). MD is an alternative emerging technology that has the potential for brine treatment for water and chemical recovery [5]. This process uses lower pressure than $\mathrm{RO}$, lower temperature than distillation processes [6] and membranes with less demanding properties as required by $\mathrm{RO}$. Salt rejections of more than $99 \%$ is possible [6]. A further advantage of the MD process is that waste or solar energy can be used to drive the process $[7,8]$.

The MD process makes use of hydrophobic microporous membranes which are claimed to be fairly resistant to membrane fouling/scaling [9]. Water and chemicals can be extracted from the brines with high water recoveries without serious fouling/scaling of the membranes. The driving force for this process is a temperature difference across the membrane for the concentration/desalination of brines [6].

Previous studies have demonstrated that a MD technique such as vacuum-enhanced direct contact membrane distillation (VEDCMD) and forward osmosis (FO) could be effectively used for RO brine treatment [10]. Water recoveries of $81 \%$ and $90 \%$ could be obtained with the treatment of $\mathrm{RO}$ brine $(7,500$ and $17,500 \mathrm{mg} / \mathrm{L})$ with VEDCMD and FO, respectively. Another study [11] has shown that an integration of DCMD with accelerated precipitation softening (APS) to protect the membranes from fouling resulted in a $98 \%$ water recovery and a permeate (condensate) with a quality of $6.0 \mu \mathrm{S} / \mathrm{cm}$. A third study shows that it is possible to produce pure water (electrical conductivity ranging between 0.55 and $3.5 \mu \mathrm{S} / \mathrm{cm}$ ) from seawater RO brines [12]. A water recovery of $90 \%$ was also achieved. Other than this, not much literature is available on the treatment of EDR or RO brines with MD. However, in recent years, membrane distillation-crystallisation (MDC) has been investigated for the recovery of valuable salts from concentrated brines produced by desalination operations [12].

MD therefore appears to be a suitable technology for the concentration/desalination of difficult to treat industrial effluents for effluent volume reduction and water recovery for reuse. However, the fouling potential of the effluents for the brines is an unknown factor as well as the required operating conditions for brine treatment. Therefore, the focus of this investigation was to evaluate MD for the concentration/desalination of difficult to treat brines resulting from the desalination of petrochemical effluents for effluent volume reduction and water recovery for reuse.

\section{1. $M D$ - Principles of operation}

MD is a process in which microporous hydrophobic membranes are used to separate water from a salt solution using temperature as the driving force for desalination. The applied temperature difference across the membrane results in a vapour pressure difference which drives vapour molecules from the high vapour pressure to the low vapour pressure side through the pores of the membrane. The MD separation mechanism is based on the vapour/liquid equilibrium which implies that the component with the highest partial pressure exhibits the highest permeation rate [13].

A warm feed solution is brought into contact with at least one side (feed side) of the membrane. The hydrophobic nature of the membrane prevents the penetration of the aqueous solution into the pores, resulting in a vapour-liquid interface at each pore entrance.

\subsection{Types of $M D$}

Various types of MD configurations are available that can be used for different applications (Fig. 1). The configurations that are commonly used include [14]:

- Direct contact membrane distillation (DCMD) - It is a MD process in which a liquid phase is in contact with both sides of the membrane.

- Air gap membrane distillation (AGMD) - It is a MD process in which only the feed phase is in contact with the membrane. The condensate side consists of an air gap and a condensing surface.

- Sweeping gas membrane distillation (SGMD) - The SGMD process is a MD process with a configuration that is similar to that of AGMD. The only difference between these two processes is that the stagnant air is replaced by a moving inert gas stream (typically air) that sweeps the condensate side of the membrane carrying the vapour molecules.

- Vacuum membrane distillation (VMG) - A vacuum is applied to the permeate side of the membrane module by means of a vacuum pump.

The brine solutions that were used in this investigation were dilute and should not cause damage to the experimental apparatus. Direct contact MD was selected for this investigation because it is the easiest system to operate.

\section{Materials and methods}

\subsection{Feed solutions}

Three feed solutions were used: synthetic $\mathrm{NaCl}$ solutions, EDR and $\mathrm{RO}$ brines. The synthetic $\mathrm{NaCl}$ 
a)

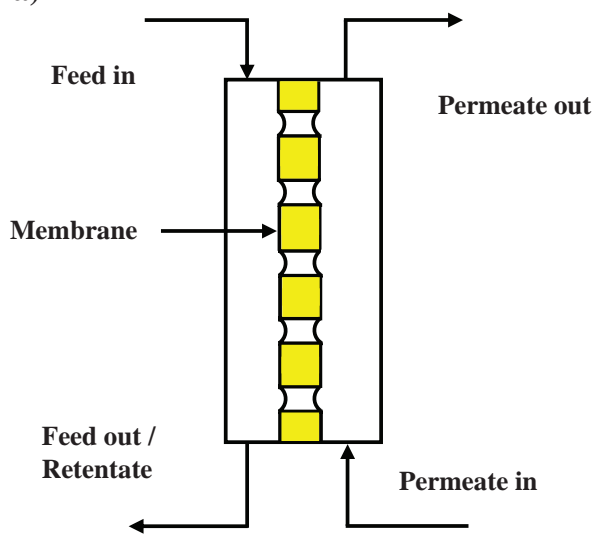

c)

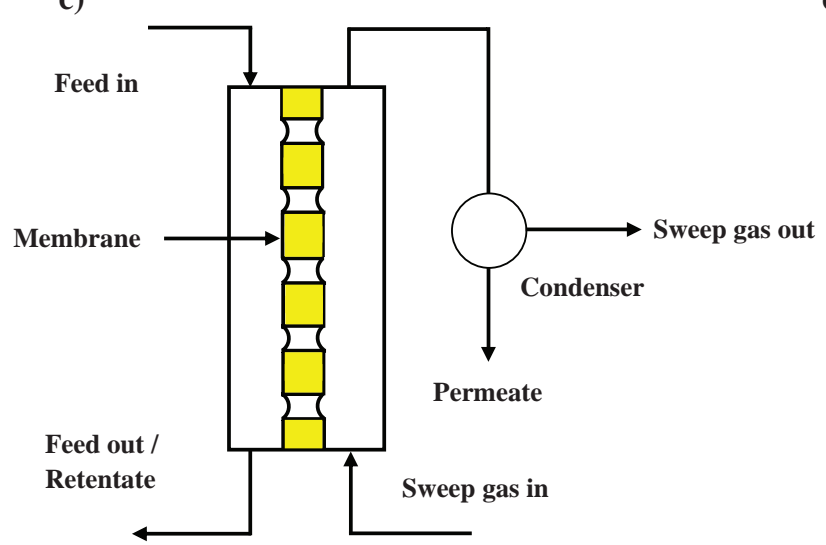

b)

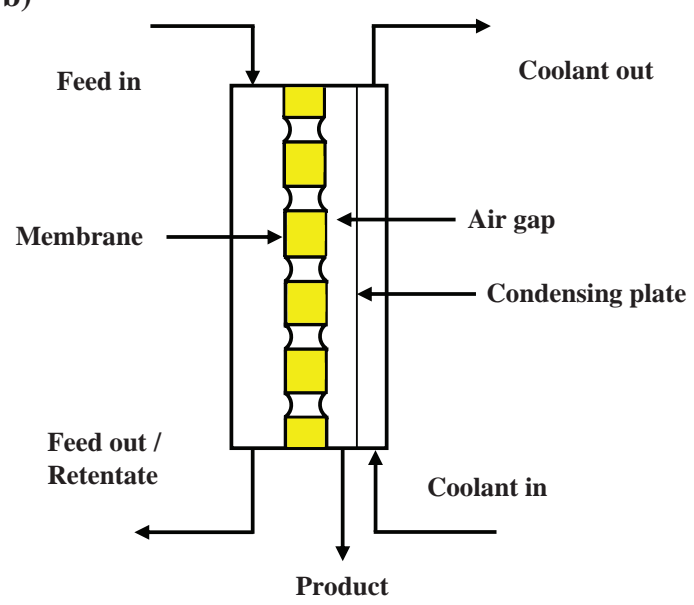

d)

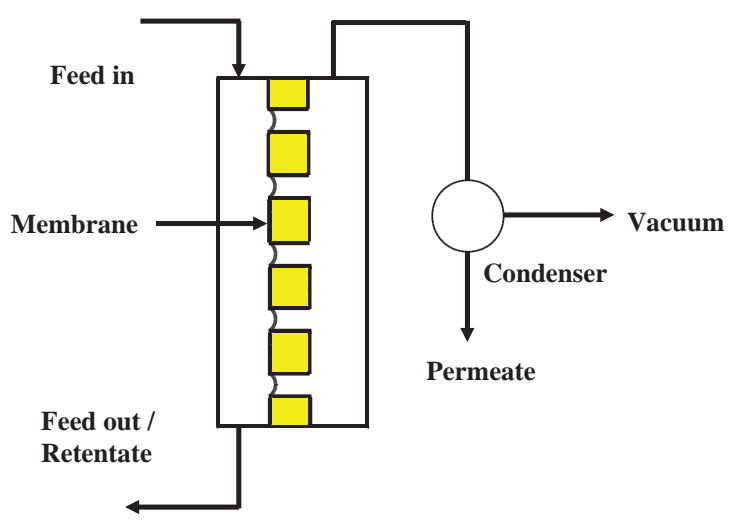

Fig. 1. Different MD configurations: (a) DCMD, (b) AGMD, (c) SGMD and (d) VMD.

solutions were prepared by dissolving the salt in tap water to obtain a $2.5 \%$ wt $\mathrm{NaCl}$ solution. The EDR and $\mathrm{RO}$ brines were obtained from an industrial petrochemical company.

The RO and EDR brines result from the treatment of different petrochemical process effluents and mine water with tubular RO and EDR, respectively [15]. The process effluents are pretreated with sandfiltration and with chemical addition for suspended solids and iron and manganese removal, respectively. The TDS of the feed to the RO plant can be as high as 4,000 $\mathrm{mg} / \mathrm{L}$. The approximate concentrations of other ions and organics are: $\mathrm{Na}(900 \mathrm{mg} / \mathrm{L}) ; \mathrm{Ca}(422 \mathrm{mg} / \mathrm{L}) ; \mathrm{Ba}(0.2 \mathrm{mg} / \mathrm{l}) ; \mathrm{Cl}$ $(800 \mathrm{mg} / \mathrm{L}) ; \mathrm{SO}_{4}(3,204 \mathrm{mg} / \mathrm{L}) ; \mathrm{F}(18 \mathrm{mg} / \mathrm{L})$ and TOC (51 mg/L).

The EDR brine results from the treatment of acid mine drainage from a nearby coal mine to supplement process water to the petrochemical company. Pretreatment of the feed water to the EDR plant consists of suspended solids (filtration) and iron and manganese (chemical) removal. The TDS of the feed water to the EDR plant can be as high as $5,400 \mathrm{mg} / \mathrm{L}$. The approximate concentrations of the other ions and organics are: $\mathrm{Na}(1,100 \mathrm{mg} / \mathrm{L}) ; \mathrm{Ca}(200 \mathrm{mg} / \mathrm{L}) ; \mathrm{Cl}$ (289 mg/1); $\mathrm{SO}_{4}(3,200 \mathrm{mg} / \mathrm{l})$; TOC (2.0 mg/L). The partial chemical composition of the $\mathrm{RO}$ and EDR brines during treatment with MD is shown in Tables 1 and 2 .

Table 1

Chemical composition of the initial $\mathrm{RO}$ feed and final $\mathrm{RO}$ brine

\begin{tabular}{llll}
\hline Constituents & RO feed & RO brine & $\begin{array}{l}\text { Brine/Feed } \\
\text { ratio }\end{array}$ \\
\hline Sulphate as $\mathrm{SO}_{4}$ & 1548 & 7325 & 4.7 \\
Calcium as Ca & 2914 & 14360 & 4.9 \\
Chloride as Cl & 4485 & 20334 & 4.5 \\
$\begin{array}{l}\text { Fluoride as F } \\
\text { pH }\end{array}$ & 10 & 42 & 4.2 \\
$\begin{array}{l}\text { Conductivity } \\
\quad(\mathrm{mS} / \mathrm{cm})\end{array}$ & 6.8 & 7.6 & \\
\hline
\end{tabular}

Concentration in $\mathrm{mg} / \mathrm{L}$ unless otherwise stated 
Table 2

Chemical composition of the initial EDR feed and final EDR brine

\begin{tabular}{llll}
\hline Constituents & EDR feed & EDR brine & $\begin{array}{l}\text { Brine/Feed } \\
\text { ratio }\end{array}$ \\
\hline Sulphate as $\mathrm{SO}_{4}$ & 4053 & 24503 & 6.05 \\
Calcium as $\mathrm{Ca}$ & 324 & 403 & 1.24 \\
$\mathrm{pH}$ & 6.8 & 7.6 & \\
$\begin{array}{l}\text { Conductivity } \\
(\mathrm{mS} / \mathrm{cm})\end{array}$ & 9.5 & 38.9 & 4.1 \\
\hline
\end{tabular}

Concentration in $\mathrm{mg} / \mathrm{L}$ unless otherwise stated.

\subsection{DCMD setup}

The experimental set-up was a custom built MD system which consisted of a membrane module in which a heated process fluid and cooling water flowed in counter-current directions (Fig. 2).

A mMicrodyn hollow fibre membrane module (MD 020 CP 2N) was used. The membrane module contains 40 hydrophobic polypropylene hollow fibres of $0.1 \mathrm{~m}^{2}$ total interfacial area. The nominal pore size of the membranes was $0.2 \mu \mathrm{m}$ and the external and internal diameters were 2.8 and $1.5 \mathrm{~mm}$, respectively. The membrane thickness was $120 \mu \mathrm{m}$ with $70 \%$ porosity.

Digital thermocouples (resolution of $0.1^{\circ} \mathrm{C}$ and accuracy of $\pm 1^{\circ} \mathrm{C}$ ) and pressure gauges (range of $0-100 \mathrm{kPa}$ ) were attached to the inlet and outlet of the MD module, and were used to monitor the temperatures and pressures of the fluids, respectively. A water bath was used to heat the feed solution and the condensate and the pick-up water (C\&PUW) were recirculated through a coil immersed in a cooling/chiller unit. Experiments were conducted in the batch mode where the C\&PUW, and the retentate stream, flowed countercurrent through the membrane. Both the feed and the cooling water (C\&PUW) were recirculated by means of Watson Marlow peristaltic pumps $(0.25 \mathrm{~kW} 3-$ phase $50 \mathrm{~Hz}$ ). Silicon pipes, with inner and outer diameters of 5 and $10 \mathrm{~mm}$, respectively, were used. The feed and C\&PUW tanks were modified Erlenmeyer flasks of approximately 3 litres in volume. The water vapour from the process was collected in the C\&PUW tank which was weighed continuously with a measuring balance. Readings were taken approximately every hour. The quality of the feed and the C\&PUW was determined by an electrical conductivity meter.

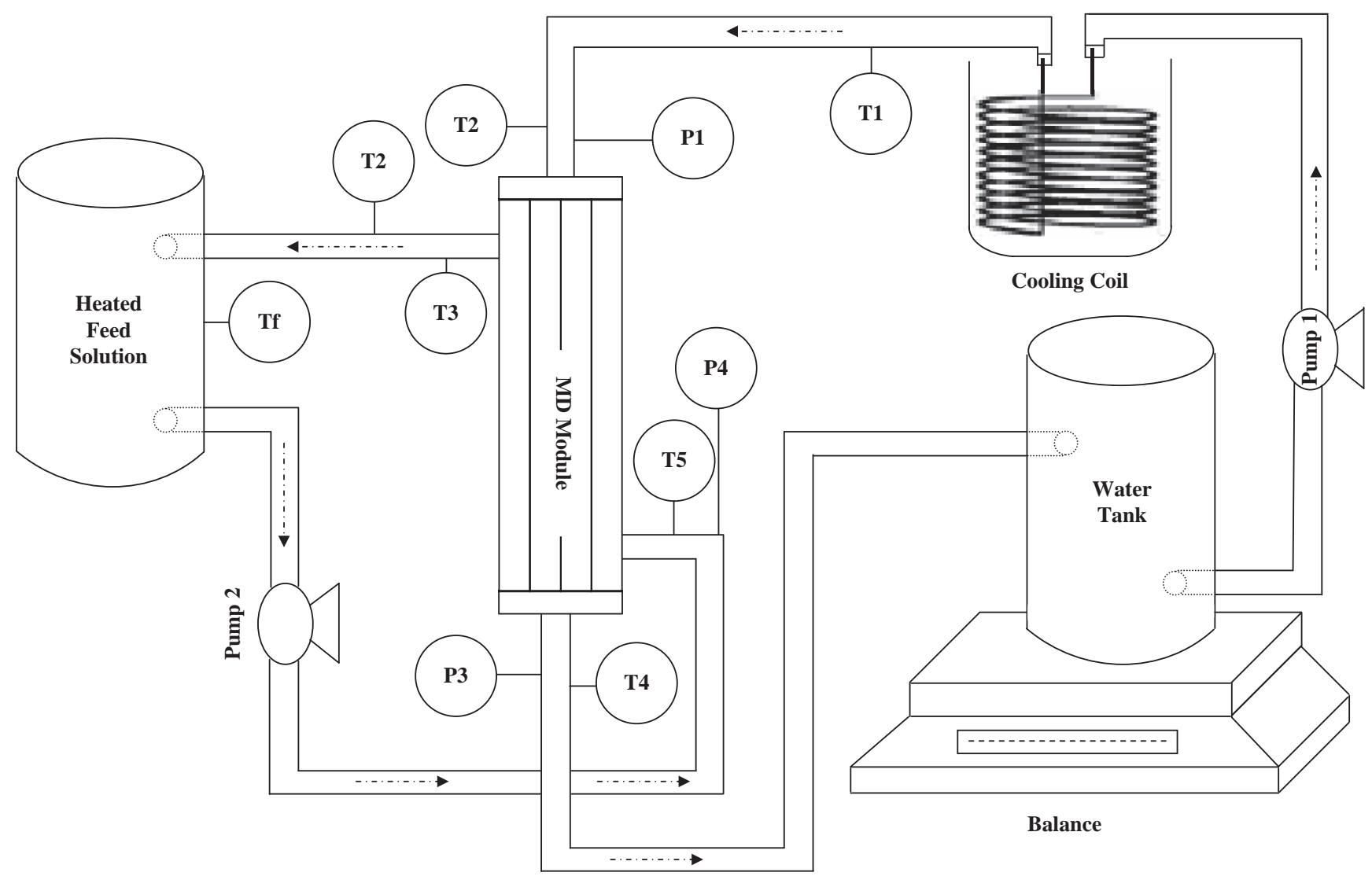

Fig. 2. Schematic sketch of the experimental set-up. 


\subsection{Membrane cleaning}

Hydrochloric acid solution $(\mathrm{pH}=1)$ and a $2.5 \mathrm{wt} \%$ $\mathrm{NaCl}$ solution ( $\mathrm{pH}$ adjusted to 11 with $\mathrm{NaOH}$ ) was used to remove precipitate and organic scale deposits, caused by the EDR and RO brines, respectively, from the membrane surface and in the MD system. Prior to any experimental work being done on the EDR and $\mathrm{RO}$ brines, the clean vapour flux (CVF) was initially measured with a $2.5 \mathrm{wt} \% \mathrm{NaCl}$ solution. The CVF (2.5 wt\% solution) was again measured after membrane cleaning to determine the effect of cleaning on membranes performance and to determine the fouling/scaling potential of the EDR and $\mathrm{RO}$ brines for the membranes. The CVF was conducted at a feed temperature $\left(T_{\mathrm{f}}\right)$ of $40^{\circ} \mathrm{C}$, a permeate temperature $\left(T_{\mathrm{p}}\right)$ of $10^{\circ} \mathrm{C}$, a feed flow rate of $1,330 \mathrm{~mL} / \mathrm{min}$ and a C\&PUW flow rate of $535 \mathrm{~mL} / \mathrm{min}$.

\section{Results and discussion}

\subsection{Treatment of a synthetic $\mathrm{NaCl}$ solution with $\mathrm{MD}$}

\subsubsection{Effect of feed temperature on the condensate flux}

The effect of feed inlet temperatures on the condensate flux is shown in Fig. 3. Condensate flux increases with increasing feed temperature from 20 to $38^{\circ} \mathrm{C}$. However, the flux decreased with time especially at the highest feed temperature as a result of concentration polarisation and/or membrane fouling/scaling. The initial increase in the flux at the highest temperature $\left(38^{\circ} \mathrm{C}\right)$ could be ascribed to temperature equilibrium that has not been properly established. The average flux values were $0.33 \mathrm{~L} \mathrm{~m}^{-2} \mathrm{~h}^{-1}\left(20^{\circ} \mathrm{C}\right), 0.47 \mathrm{~L} \mathrm{~m}^{-2} \mathrm{~h}^{-1}\left(25^{\circ} \mathrm{C}\right)$ and $1.09 \mathrm{~L} \mathrm{~m}^{-2} \mathrm{~h}^{-1}\left(38^{\circ} \mathrm{C}\right)$. This is in agreement with literature data [13].

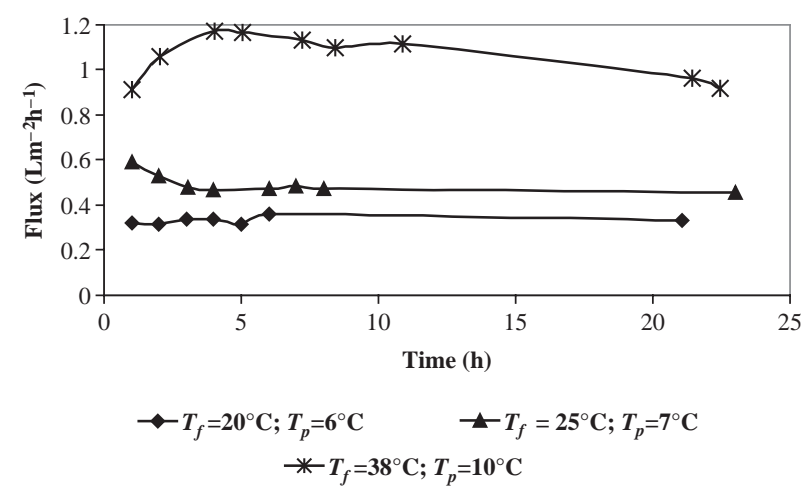

Fig. 3. Condensate flux as a function of time at different feed inlet temperatures $\left(C_{\mathrm{f}}=2.5 \mathrm{wt} \% ; T_{\mathrm{p}}=13^{\circ} \mathrm{C} ; Q_{\mathrm{f}}=\right.$ $\left.1,330 \mathrm{~mL} / \mathrm{min} ; Q_{\mathrm{p}}=535 \mathrm{~mL} / \mathrm{min}\right)$.

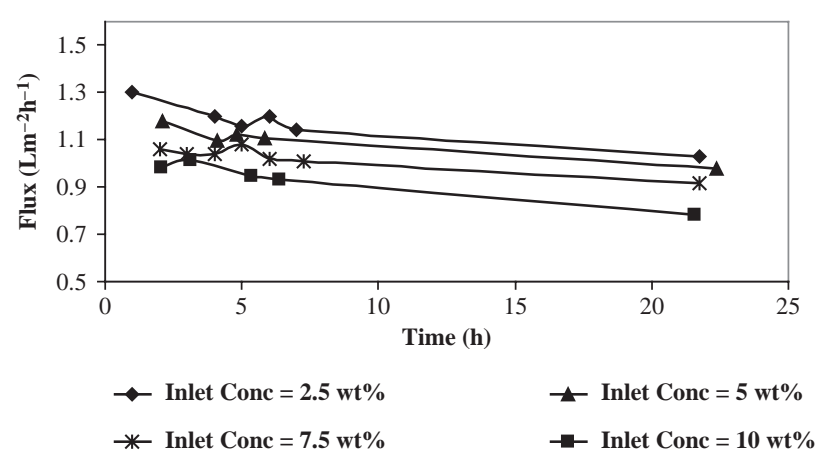

Fig. 4. Condensate flux[o1] as a function of time at different feed inlet concentrations $\left(T_{\mathrm{f}}=38^{\circ} \mathrm{C} ; T_{\mathrm{p}}=10^{\circ} \mathrm{C} ; Q_{\mathrm{f}}=\right.$ $\left.1,330 \mathrm{~mL} / \mathrm{min} ; Q_{\mathrm{p}}=535 \mathrm{~mL} / \mathrm{min}\right)$.

\subsubsection{Effect of feed concentration on condensate flux}

The effect of increasing feed inlet concentration on condensate flux is shown in Fig. 4.

Condensate flux decreases with time and increasing feed inlet concentration. This reduction can be ascribed to an increase in concentration polarisation and to the reduction in vapour pressure with increasing feed salt concentration [9]. The average flux values were $1.17 \mathrm{~L} \mathrm{~m}^{-2} \mathrm{~h}^{-1}(2.5 \mathrm{wt} \%), 1.08 \mathrm{~L} \mathrm{~m}^{-2} \mathrm{~h}^{-1}$ (5 wt \%), $1.05 \mathrm{~L} \mathrm{~m}^{-2} \mathrm{~h}^{-1}(7.5 \mathrm{wt} \%)$ and $0.92 \mathrm{~L} \mathrm{~m}^{-2} \mathrm{~h}^{-1}(10 \mathrm{wt} \%)$.

\subsubsection{Effect of feed flow rate on condensate flux}

The effect of feed flow rate on condensate flux as a function of time and feed inlet flow rate is shown in Fig. 5.

Condensate flux increases with increasing feed inlet flow rate. The increase in feed inlet flow rate increases the heat transfer coefficient in the feed side as well as reduces the effects of temperature and concentration polarization [8]. Therefore, it should be better to operate the MD process at the highest possible feed inlet flow rate. The condensate flux also decreases with time. This reduction in condensate flux can be ascribed

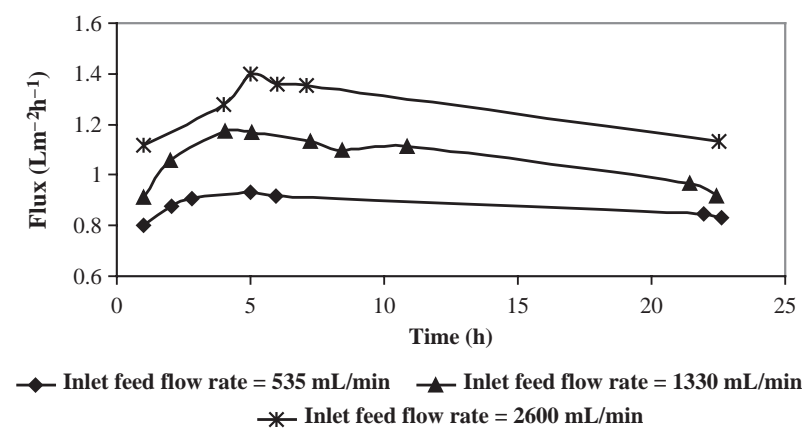

Fig. 5. Condensate flux as a function of time at different feed inlet flow rates $\left(T_{\mathrm{f}}=38^{\circ} \mathrm{C} ; T_{\mathrm{p}}=10^{\circ} \mathrm{C} ; C_{\mathrm{f}}=2.5 \mathrm{wt} \% ; Q_{\mathrm{p}}=\right.$ $535 \mathrm{~mL} / \mathrm{min}$ ). 


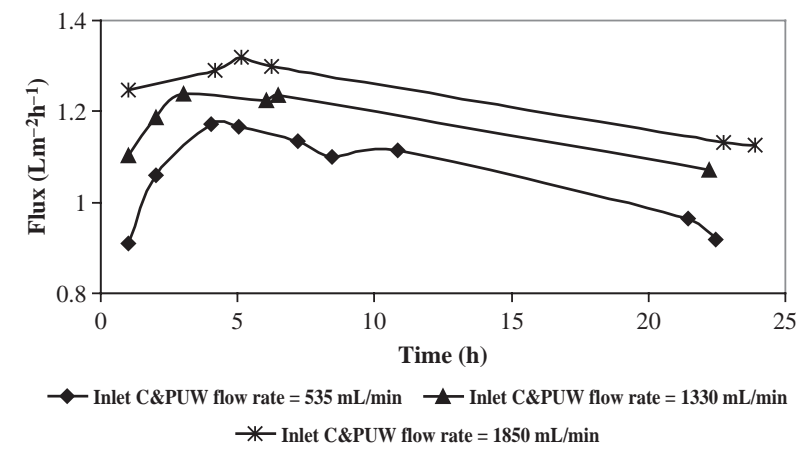

Fig. 6. Condensate flux as a function of time at different C\&PUW inlet flow rates $\left(T_{\mathrm{f}}=38^{\circ} \mathrm{C} ; T_{\mathrm{p}}=13^{\circ} \mathrm{C} ; Q_{\mathrm{f}}=\right.$ $\left.1,330 \mathrm{~mL} / \mathrm{min} ; C_{\mathrm{f}}=2.5 \mathrm{wt} \%\right)$.

to an increase in concentration polarisation [5] and possible salt crystallisation on the membrane surface. The average condensate flux values were $0.89 \mathrm{~L} \mathrm{~m}^{-2} \mathrm{~h}^{-1}$ (535 $\mathrm{mL} / \mathrm{min}), 1.09 \mathrm{~L} \mathrm{~m}^{-2} \mathrm{~h}^{-1}(1,330 \mathrm{~mL} / \mathrm{min})$ and $1.18 \mathrm{~L} \mathrm{~m}^{-2} \mathrm{~h}^{-1}(2,600 \mathrm{~mL} / \mathrm{min})$.

3.1.4. Effect of condensate pick-up flow rate on condensate flux

The effect of the C\&PUW flow rate on the condensate flux is shown in Fig. 6.

Condensate flux increases with increasing C\&PUW inlet feed flow rate. An increase in the C\&PUW inlet flow rate results in an increase in the heat transfer coefficient [9]. This means that the temperature at the membrane surface approaches the bulk condensate temperature. This causes the condensate flux to increase. The condensate flux also decreased with time at the different C\&PUW flow rates as a result of a decreasing driving force with reduced vapour pressure at the higher feed concentrations towards the end of the run. The average condensate fluxes were $1.09 \mathrm{~L} \mathrm{~m}^{-2} \mathrm{~h}^{-1}$ (535 mL/min), $1.11 \mathrm{~L} \mathrm{~m}^{-2} \mathrm{~h}^{-1}$ $(1,330 \mathrm{~mL} / \mathrm{min})$ and $1.17 \mathrm{~L} \mathrm{~m}^{-2} \mathrm{~h}^{-1}(1,850 \mathrm{~mL} / \mathrm{min})$ (Fig. 6). Therefore, the condensate flux was about $12 \%$ higher at the highest C\&PUW flow rate.

\subsection{Treatment of EDR and RO brine with $M D$}

\subsubsection{Condensate flux as a function of time and water} recovery

Condensate flux and water recovery as a function of time are shown in Fig. 7.

Condensate flux decreased with time as a result of concentration polarisation and fouling/scaling of the membranes. The initial condensate flux was $1.3 \mathrm{~L} \mathrm{~m}^{-2} \mathrm{~h}^{-1}$ and declined to $0.7 \mathrm{~L} \mathrm{~m}^{-2} \mathrm{~h}^{-1}$ after $21.5 \mathrm{~h}$ in the case of the RO brine. A steeper decline in flux was observed after $17 \mathrm{~h}$ as a result of salt

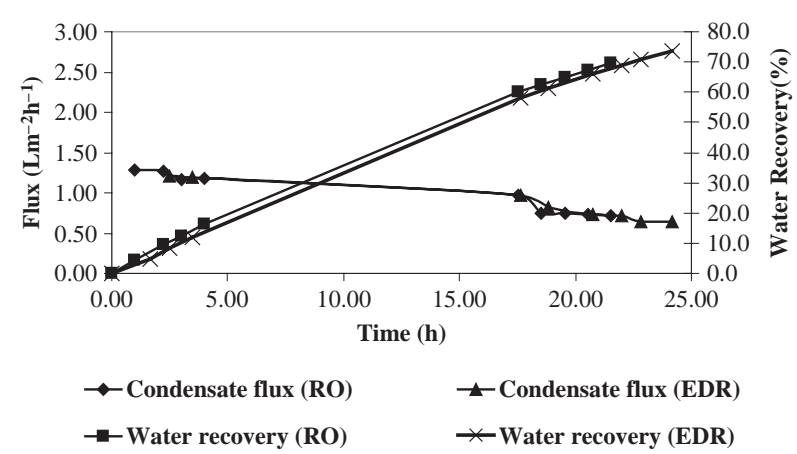

Fig. 7. Condensate flux and water recovery as a function of time $\left(T_{\mathrm{f}}=35^{\circ} \mathrm{C} ; T_{\mathrm{p}}=13^{\circ} \mathrm{C} ; Q_{\mathrm{f}}=1,330 \mathrm{~mL} / \mathrm{min} ; Q_{\mathrm{p}}=535 \mathrm{~mL} / \mathrm{min}\right)$.

precipitation that was observed in the feed tank. A similar phenomenon was observed with the EDR brine. Water recoveries at the end of the runs were $70 \%$ and $74 \%$ for the RO and EDR brines, respectively.

\subsubsection{Condensate and pick-up water and feed conductiv-} ities as a function of time

The C\&PUW and feed electrical conductivities as a function of time are shown in Fig. 8.

The C\&PUW conductivities decreased with time while the feed conductivities increased with time. The decrease in the C\&PUW conductivities is a result of the dilution of the pick-up water (tap water) with condensate with a lower conductivity than tap water. Condensate and pick-up water conductivities could be reduced from 0.31 to $0.13 \mathrm{mS} / \mathrm{cm}$ for the EDR brine and from 0.28 to $0.12 \mathrm{mS} / \mathrm{cm}$ for the $\mathrm{RO}$ brine. The electrical conductivities of the RO and EDR C\&PUW comply to the quality requirements for boiler feed make-up. The feed could be concentrated from 11 to $35 \mathrm{mS} / \mathrm{cm}$ for the RO brine and from 9.5 to $45 \mathrm{mS} / \mathrm{cm}$ for EDR brine at the end of the runs.

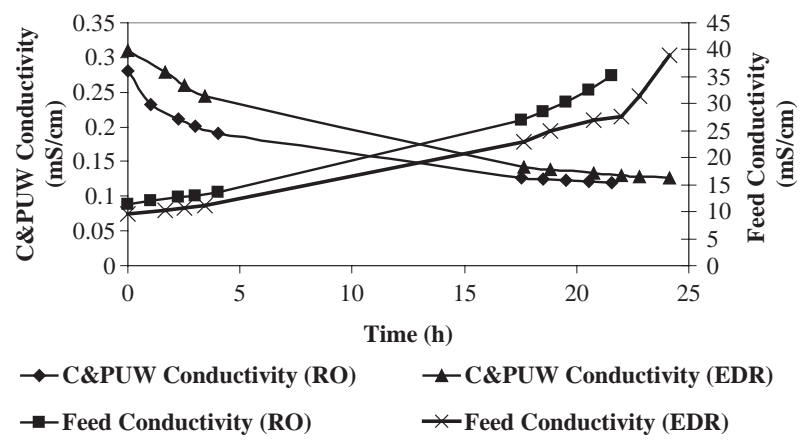

Fig. 8. Condensate and pick-up water and feed conductivities as a function of time $\left(T_{\mathrm{f}}=35^{\circ} \mathrm{C} ; T_{\mathrm{p}}=13^{\circ} \mathrm{C} ; Q_{\mathrm{f}}=1,330 \mathrm{~mL} /\right.$ $\min ; Q_{p}=535 \mathrm{~mL} / \mathrm{min}$ ). 


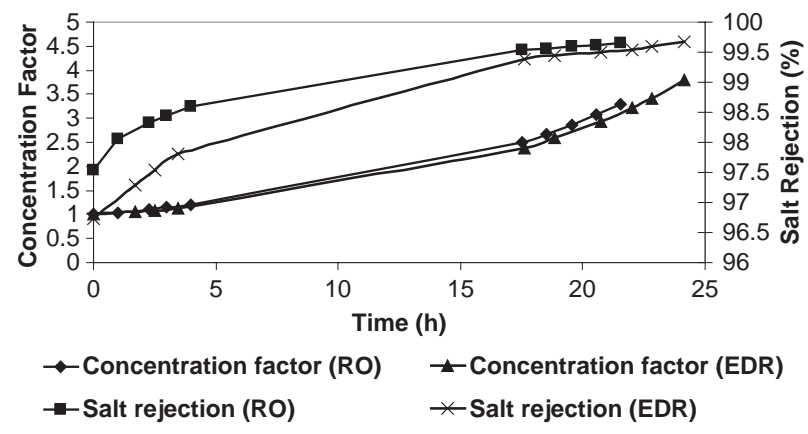

Fig. 9. Concentration factors and salt rejections as a function of time $\left(T_{\mathrm{f}}=35^{\circ} \mathrm{C} ; T_{\mathrm{p}}=13^{\circ} \mathrm{C} ; Q_{\mathrm{f}}=1,330 \mathrm{~mL} / \mathrm{min} ; Q_{\mathrm{p}}=535\right.$ $\mathrm{mL} / \mathrm{min})$.

\subsubsection{Concentration factor and salt rejection as a function} of time

The concentration factors and salt rejections as a function of time are shown in Fig. 9.

The RO and EDR brines were concentrated by factors of 3.3 and 3.8 at the end of the runs, respectively. Therefore, significant concentrations of the brines could be achieved with significant volume reductions. The brine volumes could be reduced by $70 \%$ and $74 \%$ for the RO and EDR brines, respectively. This implies that smaller brine disposal dams would be required for brine disposal.

Apparent salt rejections of $99.68 \%$ and $99.70 \%$ could be achieved in the case of RO and EDR brines, respectively (Note: All salt rejections based on C\&PUW). The high salt rejections with MD membranes will ensure that a very good quality condensate could be produced.

(Note: Salt rejection increases with time as a result of the dilution of the condensate with pick-up water).

\subsection{Fouling potential of the RO brine for the membranes}

The fouling/scaling potential of the $\mathrm{RO}$ brine for the membranes is shown in Fig. 10. The condensate flux declined with time but remained more or less constant for three consecutive runs. The decline in the flux can

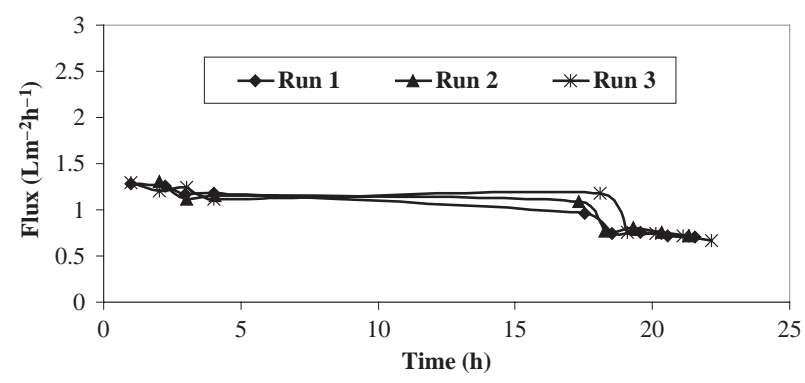

Fig. 10. Condensate flux as a function of time $\left(T_{\mathrm{f}}=35^{\circ} \mathrm{C} ; T_{\mathrm{p}}=\right.$ $13^{\circ} \mathrm{C} ; Q_{\mathrm{f}}=1,330 \mathrm{~mL} / \mathrm{min} ; Q_{\mathrm{p}}=535 \mathrm{~mL} / \mathrm{min}$ ).

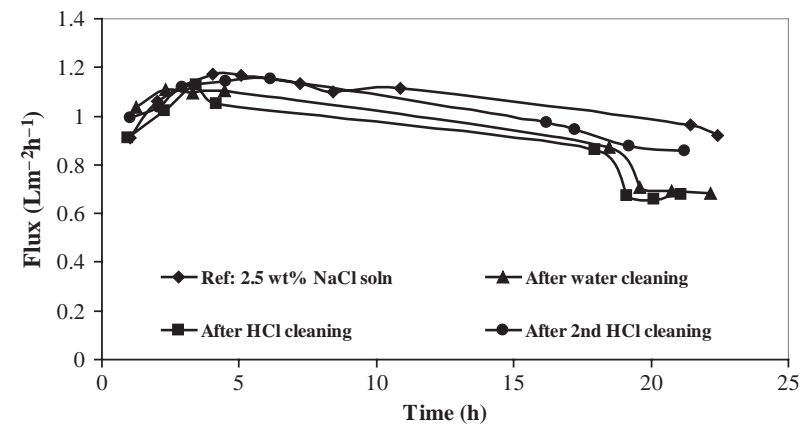

Fig. 11. Vapour flux as a function of time $\left(T_{\mathrm{f}}=35^{\circ} \mathrm{C} ; T_{\mathrm{p}}=\right.$ $13^{\circ} \mathrm{C} ; Q_{\mathrm{f}}=1,330 \mathrm{~mL} / \mathrm{min} ; Q_{\mathrm{p}}=535 \mathrm{~mL} / \mathrm{min}$ ).

be ascribed to concentration polarisation and/or fouling/scaling of the membranes. Salt crystals were detected in the feed tank. These salt crystals could have contributed to the flux decline that was experienced towards the end of the run. However, the presence of the salts in the feed did not appear to affect subsequent runs adversely. The average flux for the three consecutive runs was $0.99 \mathrm{~L} \mathrm{~m}^{-2} \mathrm{~h}^{-1}$ (Run 1), $1.00 \mathrm{~L} \mathrm{~m}^{-2} \mathrm{~h}^{-1}$ (Run 2) and $0.98 \mathrm{~L} \mathrm{~m}^{-2} \mathrm{~h}^{-1}$ (Run 3).

The CVFs before and after treatment are shown in Fig. 11. The CVF was lower (approximately 14\%) after the runs. Acid cleaning does not appear to restore flux. However, cleaning of the membranes with salt/caustic solution almost restored the flux.

3.3.1. Chemical composition of the initial RO feed and final RO brine

The chemical composition of the initial RO feed and final $\mathrm{RO}$ brine is shown in Table 1 . The salinity in the $\mathrm{RO}$ brine could be concentrated by a factor of 4.05. The final brine was supersaturated with calcium sulphate and an XRD analysis showed that the precipitate formed consisted of a mixture of sodium sulphate $\left(\mathrm{Na}_{2} \mathrm{SO}_{4}\right)$, sodium chloride $(\mathrm{NaCl})$, calcium sulphate $\left(\mathrm{CaSO}_{4}\right)$, calcium carbonate $\left(\mathrm{CaCO}_{3}\right)$ and glauberite $\left(\mathrm{Na}_{2} \mathrm{Ca}\left(\mathrm{SO}_{4}\right)_{2}\right)$.

\subsection{Fouling potential of the EDR brine for the membranes}

The fouling/scaling potential of the EDR brine for the membranes is shown in Fig. 12. The condensate flux decreased with time but also remained more or less constant for three consecutive runs. The decline in the flux can be ascribed to concentration polarisation and/or fouling/scaling of the membranes. Salt crystals were observed in the feed tank. Despite the presence of salt crystals in the feed it was shown that membrane fouling/scaling should not be a big issue in the concentration/desalination of the EDR brine with MD. The average flux for the three consecutive runs was 


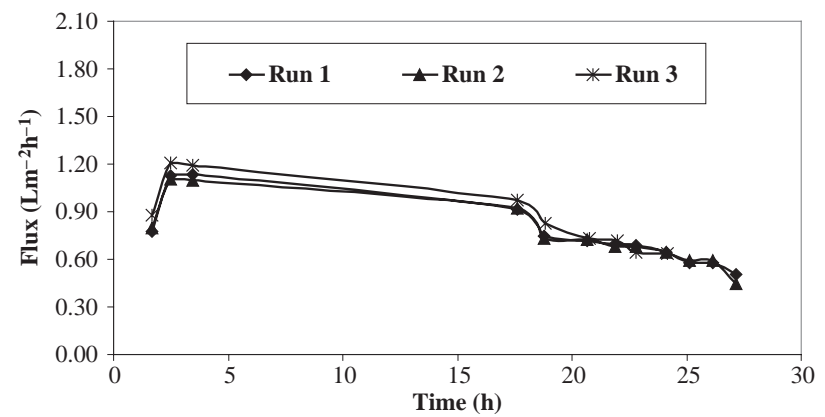

Fig. 12. Condensate flux as a function of time $\left(T_{\mathrm{f}}=34^{\circ} \mathrm{C} ; T_{\mathrm{p}}=\right.$ $\left.12^{\circ} \mathrm{C} ; Q_{\mathrm{f}}=1,330 \mathrm{~mL} / \mathrm{min} ; Q_{\mathrm{p}}=535 \mathrm{~mL} / \mathrm{min}\right)$.

$0.76 \mathrm{~L} \mathrm{~m}^{-2} \mathrm{~h}^{-1}$ (Run 1), $0.75 \mathrm{~L} \mathrm{~m}^{-2} \mathrm{~h}^{-1}$ (Run 2) and $0.74 \mathrm{~L} \mathrm{~m}^{-2} \mathrm{~h}^{-1}$ (Run 3).

The CVFs before and after the runs are shown in Fig. 13. The CVF was lower (approximately 17\%) after the runs. However, cleaning of the membranes with acid solution almost restored the flux.

\subsubsection{Chemical composition of the initial EDR feed and} final EDR brine

The chemical composition of the initial EDR feed and final EDR brine is shown in Table 2.

The salinity in the EDR brine was concentrated 4.1 times. The brine contained very high concentrations of calcium sulphate and crystals were detected in the feed tank. X-ray diffraction (XRD) analysis of the crystals showed that it consisted of calcium sulphate hydrate $\left(\mathrm{CaSO}_{4}\right)\left(\mathrm{H}_{2} \mathrm{O}\right)_{2}$. The salt crystals are most probably responsible for the reduced output of the condensate during MD of the effluent.

\section{Summary and conclusions}

\subsection{Synthetic $\mathrm{NaCl}$ solutions}

Sodium chloride feed solutions (2.5; 5.0; 7.5; and $10.0 \mathrm{wt} \%$ ) were successfully concentrated with MD. Increasing the feed temperature $(20 ; 25$ and

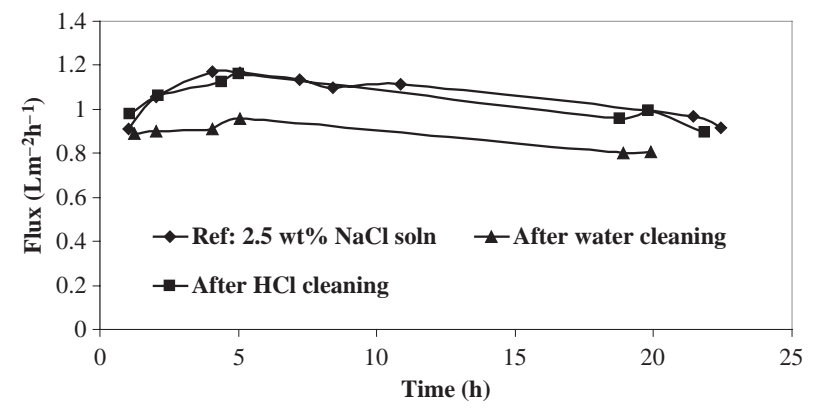

Fig. 13. Condensate flux as a function of time $\left(T_{\mathrm{f}}=38^{\circ} \mathrm{C} ; T_{\mathrm{p}}=\right.$ $\left.11^{\circ} \mathrm{C} ; Q_{\mathrm{f}}=1,330 \mathrm{~mL} / \mathrm{min} ; Q_{\mathrm{p}}=535 \mathrm{~mL} / \mathrm{min}\right)$. $38^{\circ} \mathrm{C}$ ) increases the condensate flux $(0.33 ; 0.47$ and 1.09 $\mathrm{L} \mathrm{m}^{-2} \mathrm{~h}^{-1}$, respectively).

An increase in $\mathrm{NaCl}$ feed solution concentration $(2.5 ; 5.0 ; 7.5$; and $10.0 \mathrm{wt} \%)$ results in a decrease in the condensate flux $\left(1.17 ; 1.08 ; 1.05\right.$; and $0.92 \mathrm{~L} \mathrm{~m}^{-2} \mathrm{~h}^{-1}$, respectively) as well as a decrease in temperature polarisation effects.

An increase in the feed flowrate $(535 ; 1,330$ and $2,600 \mathrm{~mL} / \mathrm{min})$ increases the condensate flux $(0.89$; 1.09 and $1.18 \mathrm{~L} \mathrm{~m}^{-2} \mathrm{~h}^{-1}$, respectively) but to a smaller degree than for an increase in the feed temperature. An increase in the C\&PUW flow rates $(535 ; 1,330 \mathrm{~mL} / \mathrm{min}$ and $1,850 \mathrm{~mL} / \mathrm{min}$ ) also increases the condensate flux (1.09; 1.11 and $1.17 \mathrm{~L} \mathrm{~m}^{-2} \mathrm{~h}^{-1}$, respectively) but also to a smaller degree.

\subsection{RO brine}

The RO brine was successfully concentrated/desalinated by DCMD. Salt rejections, water recoveries and C\&PUW conductivities were: water recovery (\%): 70, salt rejection (\%): 99.7, condensate and pick-up water quality $(\mu \mathrm{S} / \mathrm{cm}): 120.3$.

The C\&PUW quality $(<125 \mu \mathrm{S} / \mathrm{cm})$ produced from the brine should be suitable for boiler feed make-up.

The condensate flux $\left(0.99 ; 1.00\right.$ and $\left.0.98 \mathrm{~L} \mathrm{~m}^{-2} \mathrm{~h}^{-1}\right)$ remained more or less the same for three consecutive runs but decreased with time. The decline in the flux could be ascribed to concentration polarisation and/ or fouling/scaling of the membranes. The CVF was approximately $14 \%$ lower after the runs. Acid cleaning could not restore flux. However, cleaning of the membranes with salt/caustic solution almost restored the flux.

Crystals were detected in the MD brine. A mixture of sodium sulphate $\left(\mathrm{Na}_{2} \mathrm{SO}_{4}\right)$, sodium chloride $(\mathrm{NaCl})$, calcium sulphate $\left(\mathrm{CaSO}_{4}\right)$, calcium carbonate $\left(\mathrm{CaCO}_{3}\right)$ and glauberite $\left(\mathrm{Na}_{2} \mathrm{Ca}\left(\mathrm{SO}_{4}\right)_{2}\right)$ formed.

\subsection{EDR brine}

The EDR brine was successfully concentrated / desalinated by DCMD. The salt rejections, water recoveries and C\&PUW conductivities were: water recovery (\%): 74, salt rejection (\%): 99.66, condensate and pickup water quality $(\mu \mathrm{S} / \mathrm{cm}): 122.3$.

The C\&PUW quality $(<125 \mu \mathrm{S} / \mathrm{cm})$ should be suitable for boiler feed make-up.

The condensate flux $\left(0.76,0.75\right.$ and $\left.0.74 \mathrm{~L} \mathrm{~m}^{-2} \mathrm{~h}^{-1}\right)$ also remained more or less the same for three consecutive runs but decreased with time. The decline in the flux could be ascribed to concentration polarisation and/or fouling/scaling of the membranes. The CVF was approximately $17 \%$ lower after the runs. Acid 
cleaning did not restore flux. However, cleaning of the membranes with a salt/caustic solution almost restored the flux. Crystals were detected in the MD brine. XRD analysis showed these to be calcium sulphate hydrate $\left(\mathrm{CaSO}_{4}\right)\left(\mathrm{H}_{2} \mathrm{O}\right)_{2}$ crystals.

\section{References}

[1] M. Ahmed, A. Arakel, D. Hoey, M.R. Thumarukudy, M.F.A. Goosen, M. Al-Haddabi, M. and A. Al-Belushi, Feasibility of salt production from inland $\mathrm{RO}$ desalination plant reject brine: a case study, Desalination, 158 (2003) 109-117.

[2] S. Al-Obaidani, E. Curcio, F. Macedonio, G. Di Profio, H. AlHinai and E. Drioli, Potential of membrane distillation in seawater desalination: Thermal efficiency, sensitivity study and cost estimation, J. Membr. Sci., 323 (2008) 85-98.

[3] L.F. Greenlee, D.F. Lawler, B.D. Freeman, B. Marrot, and P. Moulin, Reverse osmosis desalination: Water sources, technology and today's challenges, Water Res., 43 (2009) 2317-2348.

[4] N. Dow, J. Zhang, M. Duke, J. Li, S.R. Gray, and E. Ostarcevic, Membrane distillation of Brine Wastes, Division of Water Technology, CSIR, CRC for water quality and treatment - Research Report 63, Water Quality Research Australia, Adelaide.

[5] L. Mariah, C.A. Buckley, C.J. Brouckaert, E. Curcio, E. Drioli, D. Jaganyi and D. Ramjugernath, Membrane distillation of concentrated brines - role of water activities in the evaluation of the driving force, J. Membr. Sci., 280 (2006) 937-947.
[6] K.W. Lawson and D.R. Lloyd, Review membrane distillation, J. Membr. Sci., 124 (1997) 1-25.

[7] F.A. Banat and J. Simandl, Theoretical and experimental study in membrane distillation, Desalination, 95 (1994) 39-52.

[8] X. Wang, L. Zhang, H. Yang and H. Chen, Feasibility research of potable water production via solar-heated hollow fiber membrane distillation system, Desalination, 247 (2009) 403-411.

[9] M.S. El-Bourawi, Z. Ding, R. Ma and M. Khayet, Review a framework for better understanding membrane distillation separation process, J. Membr. Sci., 285 (2006) 4-29.

[10] C.R. Martinetti, A.E. Childress and T.Y. Cath, High recovery of RO brines using forward osmosis and membrane distillation, J. Membr. Sci., 331 (2009) 31-39.

[11] D. Qu, J. Wang, L. Wang, D. Hou, Z. Luan and B. Wang, Integration of accelerated particle softening with membrane distillation for high-recovery of primary reverse osmosis concentrate, Sep. Purif. Technol., 67(2009) 21-25.

[12] L. Baratta, Boiler feed water make-up, personal communication, Sasol.

[13] M. Tomaszewska, Membrane distillation-examples of application in technology and environmental protection, Pol. J. Environ. Stud., 9 (1) (2000) 27-36.

[14] M. Gryta, Osmotic MD and other membrane distillation variants, J. Membr. Sci., 246 (2005) 145-156.

[15] J.J. Schoeman, J.G. Nieuwenhuis, L.H. Van der Merwe, and S. Marais, An overview of water desalination activities in the South African petrochemical, power and water supply industries, In IDS 6th Annual Conference, Upgrading Groundwater and Recycled Water by Desalination, 2003, pp. 155-169. 